\title{
28 Research Square \\ Relationship Between GIP Receptor Gene Polymorphism rs10423928 and Bone Mineral Density in Postmenopausal Women in Shanghai
}

\author{
Lizhi Zhang \\ Jiangqiao hospital Jiading district https://orcid.org/0000-0002-9585-1435 \\ Jinwei He \\ Shanghai Sixth Peoples Hospital \\ Xiang Sun \\ Shanghai Institute of Technology \\ Dongyue Pang \\ Jiangqiao hospital Jiading district \\ Jingjing Hu \\ Jiangqiao hospital Jiading district \\ Bo Feng ( $\sim$ fengbodfyy@tongji.edu.cn ) \\ Shanghai Dongfang Hospital: Shanghai East Hospital
}

\section{Research}

Keywords: osteoporosis, glucose-dependent insulinotropic peptide, Single-nucleotidepolymorphisms, Polymorphism, Haplotypes, Bone mineral density

Posted Date: December 11th, 2020

DOI: https://doi.org/10.21203/rs.3.rs-123626/v1

License: (9) (i) This work is licensed under a Creative Commons Attribution 4.0 International License. Read Full License 


\section{Abstract}

Background: GIP (glucose-dependent insulinotropic peptide) has been found to affect bone metabolism. GIPR single nucleotide polymorphism (SNP) is related to its activity, but the relationship between GIPR SNP and osteoporosis in postmenopausal women is still unclear. The Aim of this study was to investigate the association between GIPR SNP and bone mineral density (BMD) in postmenopausal women in Shanghai.

Methods: GIP SNP rs10423928 was detected in 884 postmenopausal women in Shanghai. The correlation between GIPR SNP and BMD was further assessed.

Results: There was a statistical difference between the dominant model of this site rs10423928 and the bone mineral density of the femoral neck $(P=0.035)$ and the Wards triangle area $(P=0.033)$.

Conclusions: The rs 10423928 of GIPR is related to the BMD of postmenopausal women in Shanghai, China.

\section{Background}

Postmenopausal osteoporosis is related to aging and seriously affects the health of postmenopausal women. Bone mineral density (BMD) is the most commonly used indicator for the diagnosis of osteoporosis, and $60-80 \%$ of its variation is determined by genetic factors(1).

Studies have found that some commonly used drugs that regulate blood sugar, such as glucagon-like peptide-1 (GLP-1) receptor agonist, DPP-4 inhibitor (DPP-4i), can inhibit bone resorption and improve bone formation (2-7). GLP-1 is one of the substrates of DPP-4 enzyme, and other substrates of DPP-4 such as: GIP (glucose-dependent insulinotropic peptide), GLP-2 (glucagon-like peptide-1), IGF - 1 (insulin-like growth factor-1) have also been found to affect bone metabolism, or promote bone formation, or reduce bone resorption by osteoclasts (8-11).

GIP is an intestinal insulinotropic hormone that is synthesized and secreted by $\mathrm{K}$ cells of the duodenum and jejunum, and exerts a biological effect by binding to the corresponding GIP receptor (GIPR) on the cell surface: promotes the secretion of insulin in the first phase; improves the body's sensitivity to insulin. Our previous studies have demonstrated that there was the correlation between polymorphisms of GLP-1R gene and BMD of lumbar spine, femoral neck, and total hip in postmenopausal women of Han nationality in Shanghai, China(12). Howerver, it is unclear whether there is a correlation between polymorphisms of GIPR gene and osteoporosis. So far, few studies on GIPR gene polymorphism and osteoporosis in postmenopausal women have been performed. The purpose of our research was to explore the correlation between GIPR gene polymorphism and BMD in postmenopausal women in Shanghai.

The GIP receptor (GIPR) gene is located on chromosome 19 q13.3. GIPR is widely distributed in various tissues and organs of the human body, and is most abundantly expressed in pancreatic islet $\beta$ cells,followed by islet $a$ cells(13). In addition, it is also expressed in extra-pancreatic tissues such as osteoblasts, cardiomyocytes, vascular endothelial cells, stomach, small intestine, adipose tissue, kidney and central nervous system (14). It is speculated that gene mutations or mutations encoding GIPR may lead to abnormal expression and function of GIPR, which may be related to the risk of osteoporosis. We screened for GIPR single nucleotide polymorphism (SNP) in the GIPR locus of the CHB (Han ethnic group from Beijing) population of HapMap second stage data (http://www.hapmap.org). SNP mainly refers to DNA sequence polymorphism caused by single nucleotide variation at the genome level. SNP has now become the third-generation genetic marker. Many phenotypic 
differences in human body susceptibility to drugs or diseases, etc. may be related to SNP. SNP will provide a powerful tool for the discovery of high-risk groups, the identification of disease-related genes, the design and testing of drugs, and biological basic research of science.

The 884 postmenopausal female subjects participating in the study measured lumbar spine 1-4 (L1-4), left femoral neck (Femoral neck) and total hip (Total) BMD, expressed in $\mathrm{g} / \mathrm{cm}^{2}$ using dual-energy X-ray absorptiometry (GE-LUNAR Prodigy USA). According to strict quality control requirements, the instrument is controlled by a special person and measured once with a standard phantom before use every day to evaluate the stability of the system. The coefficient of variation (CV) of lumbar spine, femoral neck, and total hip BMD measurements were $1.39 \%, 2.22 \%$, and $0.70 \%$, respectively.

This study was approved by the Ethics Committee of the Sixth People's Hospital Affiliated to Shanghai Jiaotong University, and Han women who were treated in the osteoporosis and bone disease specialty of Shanghai Sixth People's Hospital were selected. All the subjects were informed and signed the consent form.

Inclusion criteria: natural menopause lasted more than 1 year; did not receive anti-osteoporosis drugs (except calcium tablets and vitamin D); without diseases that affect bone metabolism.

We used the established postmenopausal women's database and included BMD and other clinical data to analyze the correlation between GIPR gene polymorphism and BMD of postmenopausal women in Han nationality in Shanghai. In this experiment, Shanghai Tianhao Biotechnology Co., Ltd.'s iMLDR® multiple SNP typing (15) was used to classify SNP sites.

\section{Methods}

\section{Detection of SNPs}

The selection of tag SNP is based on the International Human Genome Haplotype Program (International HapMap Project. http://www.Hapmap.org/cgi-perl/gbrowse/hapmap3_B36), and the criteria were as follows: (1) the minimum mean allele frequency (MAF) was >0.05; (2) the coefficient of link SNP linkage disequilibrium (LD) $r^{2}$ was >0.8; (3) GWAS (Genome-wide association study, genome-wide association analysis) SNPs that had been reported were included in this study. Finally, GIP site rs10423928 was detected in the present study.

Amplification was achieved by multiplex PCR reaction. Each measurable allele locus ligated product was obtained after two ligation reactions. The raw data files were analyzed using Gene Mapper 4.1 (Applied Biosystems, USA). A total of 884 postmenopausal women were analyzed. In this experiment, Shanghai Tianhao Biotechnology Co., Ltd.'s iMLDR® multiple SNP typing (15) was used to classify 1 SNP sites in 884 samples.

\section{Statistical analysis}

Statistical analysis was performed using SPSS version 24.0 (IBM SPSS Statistics 24, USA). The continuous variables with normal distribution are expressed as mean \pm standard deviation $(x \pm s)$. using SPSS version 24.0 (IBM SPSS Statistics 24, USA) The continuous variables were compared with t test between two groups; the chisquare test was used to compare the categorical variables. Haploview 4.2 was used to calculate the D' value and linkage disequilibrium coefficient $\left(r^{2}\right)$ of the linkage disequilibrium (LD) between SNPs, and the haplotype region 
and corresponding haplotype were obtained. After adjustment for age, a linear regression model was employed to assess the relationship between GIPR SNP, and BMD in postmenopausal women. A value of $P<0.05$ was considered statistically significant.

\section{Results}

\section{Characteristics of subjects}

A total of 907 postmenopausal women were included, but some subjects were excluded from this study because the samples were contamined, had poor quality or were not successfully typed after one failure. Finally,884 samples from postmenopausal women (mean age: $67.2 \pm 10.0$ years) were subjected to the detection of SNPs. In addition, subjects were divided into $<60$ years group and $\geq 60$ years group. The baseline characteristics of subjects included for final analysis are shown in Table 1. 
Table 1

Basic information of the research object

\begin{tabular}{|c|c|c|c|}
\hline Characteristics & $\begin{array}{l}\text { Age }<60 \\
(n=224)\end{array}$ & $\begin{array}{l}\text { Age } \geq 60 \\
(n=660)\end{array}$ & $\begin{array}{l}\text { P- } \\
\text { Value }\end{array}$ \\
\hline Age (year) & $54.9 \pm 5.8$ & $71.3 \pm 7.4$ & 0.00 \\
\hline Height (cm) & $156.2 \pm 5.2$ & $152.0 \pm 5.4$ & 0.00 \\
\hline Weight (kg) & $57.6 \pm 8.4$ & $55.2 \pm 8.5$ & 0.027 \\
\hline $\mathrm{BMI}\left(\mathrm{kg} / \mathrm{cm}^{2}\right)$ & $23.6 \pm 3.3$ & $23.9 \pm 3.5$ & 0.497 \\
\hline Blood calcium (mmol/L) & $2.34(2.27-2.40)$ & $2.32(2.26-2.39)$ & 0.718 \\
\hline Blood phosphorus (mmol/L) & $1.14(1.03-1.23)$ & $1.12(1.01-1.23)$ & 0.700 \\
\hline Albumin & $47.00(46.00-49.00)$ & $46.00(44.00-48.00)$ & 0.008 \\
\hline Alkaline phosphatase & $69.00(56.00-80.00)$ & $72.00(60.00-90.00)$ & 0.004 \\
\hline Creatinine & $54.00(49.00-60.75)$ & $59.00(52.00-66.00)$ & 0.00 \\
\hline $25(\mathrm{OH}) \mathrm{D}(\mathrm{ng} / \mathrm{mL})$ & $20.92(16.28-26.86)$ & $21.36(15.56-27.97)$ & 0.87 \\
\hline Parathyroid hormone & $40.65(32.82-53.34)$ & $42.37(31.63-56.22)$ & 0.128 \\
\hline$\beta$-Collagen specific sequence (ng/L) & 403.50(223.00-5630) & $366.00(216.75-551.00)$ & 0.68 \\
\hline L1-4BMD $\left(\mathrm{g} / \mathrm{cm}^{2}\right)$ & $0.894(0.806-0.992)$ & $0.859(0.773-0.968)$ & 0.008 \\
\hline Neck BMD (g/cm²) & $0.758(0.708-0.848)$ & $0.692(0.623-0.761)$ & 0.00 \\
\hline TotalBMD $\left(\mathrm{g} / \mathrm{cm}^{2}\right)$ & $0.801(0.727-0.895)$ & $0.742(0.662-0.817)$ & 0.00 \\
\hline \multicolumn{4}{|c|}{$\begin{array}{l}\text { The continuous variables of the normal distribution are represented by the mean } \pm \text { standard deviation }(x \pm s) \text {, } \\
\text { and the data of the non-normal distribution is represented by the median and the interquartile range. }\end{array}$} \\
\hline \multicolumn{4}{|c|}{$\begin{array}{l}\text { There was no significant difference in serum, calcium and phosphorus between the two groups. Alkaline } \\
\text { phosphatase was significantly higher in the group aged } \geq 60 \text { years than in the control group }(P=0.004) \text {. The } \\
\text { bone mineral density(BMD) of each group in the age group of } \geq 60 \text { years old was lower than that of the control } \\
\text { group }(P<0.001) \text {. }\end{array}$} \\
\hline
\end{tabular}

\section{Alleles frequency}

In this study, GIPR locus rs10423928 SNP was genotyped and analyzed. SNPs were examined in which the minimum allele frequency (MAF) was greater than 0.01. The genotype distribution met the Hardy-Weinberg equilibrium, and the MAF of these SNPs was similar to the genetic variation of Beijing Han population in China (CHBS). The minimum allele frequency of the GIPR locus rs 10423928 in the Han population in Beijing is $20 \%$, and it was $20.8 \%$ in our study. The results were similar(Table 2 ). 
Table 2

SNP site information of GLP-1R and GIPR genes

\begin{tabular}{|c|c|c|c|c|c|c|}
\hline SNPs & $\begin{array}{l}\text { Chr. } \\
\text { position }\end{array}$ & $\begin{array}{l}\text { SNP } \\
\text { property }\end{array}$ & Alleles & $\begin{array}{l}\text { HWE } \\
\text { P Value }\end{array}$ & $\begin{array}{l}\text { MAF in } \\
\text { CHBS }\end{array}$ & $\begin{array}{l}\text { MAF } \\
\text { In this } \\
\text { study }\end{array}$ \\
\hline rs2268657 & 39020542 & intron 1 & $\mathrm{C} / \mathrm{T}$ & 0.1902 & 0.34 & 0.326 \\
\hline rs2295006 & 46182304 & nonsynon_exon2 & $\mathrm{G} / \mathrm{A}$ & 0.7755 & 0.07 & 0.06 \\
\hline rs3765467 & 46182304 & nonsynon_exon4 & $\mathrm{G} / \mathrm{A}$ & 0.5521 & 0.23 & 0.255 \\
\hline rs6923761 & 39055485 & nonsynon_exon5 & $\mathrm{G} / \mathrm{A}$ & 1 & 0.01 & 0.01 \\
\hline rs1042044 & 39041502 & nonsynon_exon7 & $\mathrm{C} / \mathrm{A}$ & 1 & 0.47 & 0.46 \\
\hline rs2268641 & 39050266 & intron12 & $\mathrm{C} / \mathrm{T}$ & 0.5249 & 0.39 & 0.417 \\
\hline rs4714210 & 39055485 & 3'-UTR_exon13 & $G / A$ & 0.1432 & 0.29 & 0.317 \\
\hline rs10423928 & 46182304 & intron12 & $\mathrm{A} / \mathrm{T}$ & 0.9107 & 0.20 & 0.208 \\
\hline
\end{tabular}

In our study there was no linkage disequilibrium relationship between GLP-1R SNPs and GIPR locus rs10423928 SNP $\left(0.908<D^{\prime}<1\right)$. (Fig. 1).

Clinical data corresponding to GIPR SNP site rs10423928 in postmenopausal women were in Table 3. The locus rs10423928 has three genotypes: T/T, A/T, and A/A. Among them, T/T genotype accounts for 556 patients (62.9\%), A/T genotype accounts for 289 patients (32.7\%), and A/A genotype accounts for 39 patients (4.4\%).

Table 3

Clinical data corresponding to GIPR SNP site rs10423928 in postmenopausal women

\begin{tabular}{|c|c|c|c|c|c|c|c|c|}
\hline \multirow[t]{2}{*}{ rs10423928 } & $\mathbf{N}$ & Age & Height & Weight & BMI & L1-4 & $\begin{array}{l}\text { Femoral } \\
\text { neck }\end{array}$ & Total hip \\
\hline & & (years) & (cm) & (kg) & $\left(\mathrm{Kg} / \mathrm{m}^{2}\right)$ & $\mathrm{BMD}\left(\mathrm{g} / \mathrm{cm}^{2}\right)$ & $\mathrm{BMD}\left(\mathrm{g} / \mathrm{cm}^{2}\right)$ & $\operatorname{BMD}\left(\mathrm{g} / \mathrm{cm}^{2}\right)$ \\
\hline $\mathrm{T} / \mathrm{T}$ & 556 & $\begin{array}{l}67.1 \pm \\
10.1\end{array}$ & $\begin{array}{l}152.7 \\
\pm 5.5\end{array}$ & $\begin{array}{l}55.5 \pm \\
8.9\end{array}$ & $\begin{array}{l}23.8 \pm \\
3.6\end{array}$ & $\begin{array}{l}0.877 \pm \\
0.161\end{array}$ & $\begin{array}{l}0.708 \pm \\
0.120\end{array}$ & $\begin{array}{l}0.755 \pm \\
0.132\end{array}$ \\
\hline $\mathrm{A} / \mathrm{T}$ & 289 & $\begin{array}{l}67.6 \pm \\
9.8\end{array}$ & $\begin{array}{l}153.7 \\
\pm 5.7\end{array}$ & $\begin{array}{l}56.1 \pm \\
8.2\end{array}$ & $\begin{array}{l}23.7 \pm \\
3.3\end{array}$ & $\begin{array}{l}0.896 \pm \\
0.155\end{array}$ & $\begin{array}{l}0.728 \pm \\
0.119\end{array}$ & $\begin{array}{l}0.769 \pm \\
0.130\end{array}$ \\
\hline$A / A$ & 39 & $\begin{array}{l}65.4 \pm \\
9.7\end{array}$ & $\begin{array}{l}152.0 \\
\pm 5.8\end{array}$ & $\begin{array}{l}56.5 \pm \\
6.1\end{array}$ & $\begin{array}{l}24.5 \pm \\
3.0\end{array}$ & $\begin{array}{l}0.882 \pm \\
0.148\end{array}$ & $\begin{array}{l}0.719 \pm \\
0.124\end{array}$ & $\begin{array}{l}0.773 \pm \\
0.143\end{array}$ \\
\hline
\end{tabular}

The linear regression analysis was employed to evaluate the correlation between rs10423928 and BMD. There were no relationship of rs10423928 with age, height, weight and body mass index (BMI) $(P>0.05)$. A close correlation was noted between rs10423928 and femur neck BMD (Table 4). 
Table 4

Relationship between GIPR gene SNP rs10423928 and BMD in postmenopausal women

\begin{tabular}{|c|c|c|c|c|c|c|c|}
\hline \multirow[t]{2}{*}{ rs10423928 } & age & Height & Weight & BMI & L1-4 & Femur neck & Total hip \\
\hline & (years) & (cm) & (kg) & $\left(\mathrm{kg} / \mathrm{m}^{2}\right)$ & $\operatorname{BMD}\left(\mathrm{g} / \mathrm{cm}^{2}\right)$ & $\operatorname{BMD}\left(\mathrm{g} / \mathrm{cm}^{2}\right)$ & $\mathrm{BMD}\left(\mathrm{g} / \mathrm{cm}^{2}\right)$ \\
\hline P-Value dominant & 0.753 & 0.176 & 0.527 & 0.982 & 0.331 & $0.035^{\star}$ & 0.118 \\
\hline P-value recessive & 0.271 & 0.449 & 0.702 & 0.377 & 0.331 & 0.737 & 0.427 \\
\hline P-value- addictive & 0.898 & 0.403 & 0.504 & 0.725 & 0.639 & 0.059 & 0.111 \\
\hline
\end{tabular}

The relationship between locus rs10423928 and BMD was further assessed in postmenopausal women. There was a correlation between locus rs10423928 and BMD at specific site. The T/T genotype of rs10423928 was positively related to femur neck BMD and wards triangle area BMD $(P<0.05)($ Table 5$)$. 
Table 5

Linear regression analysis of GIPR gene locus rs10423928 and BMD in postmenopausal women

\begin{tabular}{|c|c|c|c|c|c|c|}
\hline \multirow[t]{2}{*}{ BMD } & \multicolumn{2}{|c|}{ dominant } & \multicolumn{2}{|c|}{ recessive } & \multicolumn{2}{|c|}{ addictive } \\
\hline & $\beta$ & $P$ value & $\beta$ & $P$ value & $\beta$ & $P$ value \\
\hline L1 & 0.014 & 0.180 & -0.004 & 0.860 & 0.010 & 0.289 \\
\hline L2 & 0.017 & 0.150 & 0.002 & 0.930 & 0.012 & 0.216 \\
\hline L3 & 0.021 & 0.123 & 0.000 & 0.988 & 0.015 & 0.194 \\
\hline L4 & 0.026 & 0.053 & 0.015 & 0.639 & 0.020 & 0.073 \\
\hline L1_2 & -0.019 & 0.296 & 0.018 & 0.671 & -0.011 & 0.468 \\
\hline L1_3 & -0.023 & 0.271 & 0.039 & 0.426 & -0.011 & 0.522 \\
\hline L1_4 & -0.021 & 0.331 & 0.050 & 0.331 & -0.009 & 0.639 \\
\hline L2_3 & -0.010 & 0.603 & 0.038 & 0.407 & -0.002 & 0.888 \\
\hline L2_4 & -0.010 & 0.611 & 0.050 & 0.297 & -0.001 & 0.956 \\
\hline L3_4 & 0.010 & 0.581 & 0.044 & 0.293 & 0.013 & 0.402 \\
\hline Neck & 0.018 & $0.035^{\star}$ & 0.007 & 0.737 & 0.013 & 0.059 \\
\hline Wards & 0.019 & $0.033^{\star}$ & 0.016 & 0.466 & 0.016 & $0.040 *$ \\
\hline Troch & 0.009 & 0.278 & 0.005 & 0.802 & 0.007 & 0.317 \\
\hline Inter & 0.017 & 0.140 & 0.032 & 0.234 & 0.016 & 0.096 \\
\hline Total & 0.014 & 0.118 & 0.017 & 0.427 & 0.012 & 0.111 \\
\hline \multicolumn{7}{|c|}{ *P $\leq 0.05$, ** $P \leq 0.01$} \\
\hline$\beta:$ Regr & ssion cc & cients & & & & \\
\hline
\end{tabular}

\section{Discussion}

Genome wide association studies (GWAS) confirmed that bone mineral density is associated with multiple genetic susceptibility regions $(16,17)$. The correlation between vitamin $D$ receptor gene polymorphism and osteoporosis was first revealed by Morrison et al (18) in 1994. Since then, more than one hundred gene polymorphisms related to bone metabolism regulation have been studied including sex hormones and their receptors, bone matrix component related genes, apolipoprotein $\mathrm{E}(\mathrm{ApoE})$, etc., the results have confirmed the important role of genetic factors in primary osteoporosis.

In the literature (19), the variation of GIPR gene SNP locus rs10423928 was associated with increased postprandial blood glucose and insulin. In addition, this locus was also associated with decreased body mass index (BMI), lean body mass and waist circumference (20). Therefore, we chose to study this site of GIPR gene. There is a strong linkage disequilibrium between rs10423928 and rs1800437 (located in exon 10, E354Q) ( $r^{2}=$ 0.99). Related studies $(21,22)$ have confirmed that mutations in rs1800437 can reduce the expression of GIPR in 
carriers. The same genetic variation is reflected in. Studies have found that patients with functional SNP loci rs10423928 linkage disequilibrium are associated with low BMD in early postmenopausal women (23).

Our study found that there is a positive correlation between the dominant model T / T of rs10423928 and BMD of the femoral neck and Wards triangle area. That is to say, if the GIPR gene rs 10423928 is homozygous T / T in postmenopausal women, it will enhance BMD of the femoral neck and Wards triangle area.

Regarding the effect of GIP on bone, a study (8) found that in mice with GIPR deficiency (GIPR KO), the cortical bone becomes thinner, the number of endosteal osteoclasts increases, and the bone mineral density decreases, which indicates the bone strength and quality variety. 14 ovariectomized 12-week-old BALB / c female mice were randomly divided into 2 groups, respectively treated with GIP analog N-AcGIP (25 nmoles / kg / day bw) and normal saline, and 10 BALB // c Female rats were injected with normal saline as a control group. Micro-CT tomography and 3D reconstruction techniques found that the number of bone trabeculae increased after GIP treatment in ovariectomized mice. TRACP staining and bone microstructure indicators suggested that the number of osteoclasts decreased and bone resorption decreased (9). (N-AcGIP: It is a GIP analogue. After acetylation of the 1 st tyrosine at the amino terminus, it can enhance the resistance to DPP-4 enzyme without being destroyed and inactivated by the enzyme.). Daily injection of GIP into Sprague-Dawley rats with ovary removed proved that GIP can inhibit the acceleration of bone turnover caused by estrogen loss (24). Studies have shown that transgenic mice overexpressing GIP have higher BMD and bone mineral content (BMC) compared to the control group. In addition, their serum GIP and total osteocalcin levels are increased (25).Gene knockout mice lacking GIPR disturb the cortical microstructure of bones, leading to a decrease in bone "quality", strength, and fat content (8). These observations indicate that there is a complex shared molecular mechanism between osteoporosis and diabetes, and incretin GIP can improve bone metabolism.

At present, it is found that GIP affects bone directly and indirectly (10). Direct route: GIP combined with GIPR on osteoblasts can increase intracellular $\mathrm{Ca}^{2}{ }^{+}$and cAMP concentrations, thereby promoting bone alkaline phosphatase activity and type I collagen mRNA expression $(14,26)$, promoting bone matrix Mineralization.In addition, the addition of GIP to the cultured osteoblast precursors can promote their differentiation, increase their proliferation and show anti-apoptotic activity in pluripotent mesenchymal stem cells in the bone marrow (27). Higher levels of transforming growth factor- $\beta$ (TGF- $\beta$ ) are known to stimulate osteoblasts, and GIP can promote the secretion of TGF- $\beta$ and improve bone metabolism. For osteoclasts, GIPR expressed in osteoclasts can downregulate bone resorption, inhibit osteoclast resorption activity, and reduce the expression of osteoclast differentiation markers (such as TRACP enzyme), as well as cathepsins $\mathrm{K}$ and the expression of G-CSF (granulocyte colony stimulating factor) receptor (28).

Indirect route: 1 . It is known that the combination of insulin and insulin receptor on the surface of osteoblast membrane will promote bone formation. GIP acts on pancreatic $\beta$ cells, enhances glucose-induced insulin secretion (19), and promotes insulin secretion.2. GIP receptors (GIPR) are also distributed on fat cells, which produce inflammatory cytokines ( such as leptin, lipase, adiponectin, amylin etc. ), GIP acts on fat cells and regulates secretion of leptin and adiponectin etc. LP can promote the differentiation of bone marrow mesenchymal stem cells into osteoblasts and inhibit their differentiation into osteoclasts and adipocytes, thereby maintaining the balance of bone metabolism, maintaining bone mass and bone quality. 3. GIP can regulate endothelial cell production of vascular endothelin-1 and nitric oxide, both of which have effects on bone turnover (29) Therefore, GIP indirectly plays an important role in the process of bone conversion (30). 
So far, only one study at home and abroad has investigated the correlation between GIPR and BMD. It is reported that patients with functional SNP loci rs10423928 linkage disequilibrium are associated with low BMD in early postmenopausal women (23). Some studies have found that GIP polymorphism is not related to serum GIP and young women; but it is inversely related to the following components in the elderly: bone strength, including density, mineral content and microstructure (31).Another study reported that postmenopausal women's serum GIP levels increased (32) and were regulated by estrogen replacement therapy (33).

About $50 \%$ of postprandial insulin secretion is the result of GIP. In type 2 diabetes patients, the insulinotropic effect of GIP has been reduced, and studies have shown that impaired GIP response is associated with insulin resistance (34). Assuming that patients with type 2 diabetes may express lesser amounts of GIPR or defective GIPR (35), then GIPR deficiency may be the pathophysiological mechanism of type 2 diabetes (36). Various intestinal hormones such as GIP and leptin can regulate bone turnover, which we call the "gut-bone axis" system, and there is a close relationship between bone turnover and intestinal hormones (37). Discussing the genetic polymorphism of intestinal hormones and their receptors can further clarify their important role in osteoporosis.

\section{Conclusion}

Our research shows that there is a positive correlation between the dominant model T / T of the polymorphism GIPR gene rs10423928 in serum and BMD of the femoral neck and Wards triangle in postmenopausal women of Han nationality in Shanghai, China. GIPR gene polymorphism SNP sites can guide the evaluation of the body's metabolic diseases. Regarding the correlation between the rest of the GIPR gene polymorphism and BMD, we will further study and confirm. This study laid a certain research foundation for clarifying the effect of GIPR on osteoporosis and diabetic osteoporosis.

\section{Abbreviations}

GIP glucose-dependent insulinotropic peptide

GIPR glucose-dependent insulinotropic peptide receptor

SNP Single-nucleotidepolymorphisms

BMD Bone mineral density

DPP-4 Dipeptidyl peptidase-4

GLP-2 glucagon-like peptide-1

IGF -1 insulin-like growth factor-1

MAF mean allele frequency

LD linkage disequilibrium

GWAS Genome-wide association study

CHBS Beijing Han population in China 
BMI body mass index

TRACP tartrate resistant acid phosphatase

G-CSF granulocyte colony stimulating factor

TGF- $\beta$ transforming growth factor- $\beta$

\section{Declarations}

\section{Ethics approval and consent to participate}

ethical approval was granted by Ethics Committee of Shanghai Sixth People's Hospital.

\section{Consent for publication}

Both written and verbal informed consent were also sought from all the participants during the data collection exercise.

\section{Availability of data and material}

All data generated or analysed during this study are included in this published article [and its supplementary information files]

\section{Competing interests}

The other authors have no conflicts of interest to declare.

\section{Funding}

This study was supported by the Pudong New Area Health and Family Planning Commission Fund Project (PWZzk2017-12).

\section{Author's contribution}

LZ and BF designed the study, LZ and JH collected the data, analyzed the data, interpreted the results and prepared the submission for publication. XS, DP and JH collected samples and data, performed data analysis and interpreted the results.

\section{Acknowledge}

We would like to thank all authors of the primary studies included in this systematic review and meta-analysis.

\section{Contributions}

(I) Conception and design: L Zhang, B Feng; (II) Administrative support: B Feng; (III) Provision of study materials or patients: J He; (IV) Collection and assembly of data: J He, L Zhang ,X Sun; (V) Data analysis and interpretation: X Sun, W He, Dongyue Pang, Jingjing Hu; (VI) Manuscript writing: All authors; (VII) Final approval of manuscript: All authors. 


\section{References}

1. Peacock M, Turner CH, Econs MJ, et al. Genetics of osteoporosis. Endocr Rev 2002;23:303-26.

2. Trujillo JM, Nuffer W. GLP-1 receptor agonists for type 2 diabetes mellitus: recent developments and emerging agents. Pharmacotherapy 2014;34:1174-86.

3. Yamada C, Yamada Y, Tsukiyama K, et al. The murine glucagon-like peptide-1 receptor is essential for control of bone resorption. Endocrinology 2008;149:574-9.

4. Ma X, Meng J, Jia M, et al. Exendin-4, a glucagon-like peptide-1 receptor agonist, prevents osteopenia by promoting bone formation and suppressing bone resorption in aged ovariectomized rats. $J$ Bone Miner Res 2013;28:1641-52.

5. Meng J, Ma X, Wang N, et al. Activation of GLP-1 Receptor Promotes Bone Marrow Stromal Cell Osteogenic Differentiation through $\beta$-Catenin. Stem Cell Reports 2016;6:579-91.

6. Monami M, Dicembrini I, Antenore A, et al. Dipeptidyl peptidase-4 inhibitors and bone fractures: a metaanalysis of randomized clinical trials. Diabetes Care 2011;34:2474-6.

7. Josse RG, Majumdar SR, Zheng Y, et al. Sitagliptin and risk of fractures in type 2 diabetes: Results from the TECOS trial. Diabetes Obes Metab 2017;19:78-86.

8. Mieczkowska A, Irwin N, Flatt PR, et al. Glucose-dependent insulinotropic polypeptide (GIP) receptor deletion leads to reduced bone strength and quality. Bone 2013;56:337-42.

9. Mabilleau G, Perrot R, Mieczkowska A, et al. Glucose-dependent insulinotropic polypeptide (GIP) dosedependently reduces osteoclast differentiation and resorption. Bone 2016;91:102-12.

10. Mabilleau G. Incretins and bone: friend or foe? Curr Opin Pharmacol 2015;22:72-8.

11. Glorie L, D'Haese PC, Verhulst A. Boning up on DPP4, DPP4 substrates, and DPP4-adipokine interactions: Logical reasoning and known facts about bone related effects of DPP4 inhibitors. Bone 2016;92:37-49.

12. Zhang $L$, He J, Sun $X$, et al. Relationship between glucagon-like peptide-1 receptor gene polymorphism and bone mineral density in postmenopausal women in Shanghai. Ann Palliat Med 2020.

13. Fujita Y, Wideman RD, Asadi A, et al. Glucose-dependent insulinotropic polypeptide is expressed in pancreatic islet alpha-cells and promotes insulin secretion. Gastroenterology 2010;138:1966-75.

14. Baggio LL, Drucker DJ. Biology of incretins: GLP-1 and GIP. Gastroenterology 2007;132:2131-57.

15. Zhang XY, He JW, Fu WZ, et al. Associations of Serum Osteocalcin and Polymorphisms of the Osteocalcin Gene with Bone Mineral Density in Postmenopausal and Elderly Chinese Women. J Nutrigenet Nutrigenomics 2016;9:231-42.

16. Styrkarsdottir U, Halldorsson BV, Gretarsdottir S, et al. Multiple genetic loci for bone mineral density and fractures. N Engl J Med 2008;358:2355-65.

17. Rivadeneira F, Styrkársdottir U, Estrada K, et al. Twenty bone-mineral-density loci identified by large-scale meta-analysis of genome-wide association studies. Nat Genet 2009;41:1199-206.

18. Morrison NA, Qi JC, Tokita A, et al. Prediction of bone density from vitamin D receptor alleles. Nature 1994;367:284-7.

19. Saxena R, Hivert MF, Langenberg C, et al. Genetic variation in GIPR influences the glucose and insulin responses to an oral glucose challenge. Nat Genet 2010;42:142-8. 
20. Lyssenko V, Eliasson L, Kotova O, et al. Pleiotropic effects of GIP on islet function involve osteopontin. Diabetes 2011;60:2424-33.

21. Fortin JP, Schroeder JC, Zhu Y, et al. Pharmacological characterization of human incretin receptor missense variants. J Pharmacol Exp Ther 2010;332:274-80.

22. Mohammad S, Patel RT, Bruno J, et al. A naturally occurring GIP receptor variant undergoes enhanced agonistinduced desensitization, which impairs GIP control of adipose insulin sensitivity. Mol Cell Biol 2014;34:361829.

23. Torekov SS, Harsløf T, Rejnmark L, et al. A functional amino acid substitution in the glucose-dependent insulinotropic polypeptide receptor (GIPR) gene is associated with lower bone mineral density and increased fracture risk. J Clin Endocrinol Metab 2014;99:E729-33.

24. Bollag RJ, Zhong Q, Ding KH, et al. Glucose-dependent insulinotropic peptide is an integrative hormone with osteotropic effects. Mol Cell Endocrinol 2001;177:35-41.

25. Ding KH, Shi XM, Zhong Q, et al. Impact of glucose-dependent insulinotropic peptide on age-induced bone loss. J Bone Miner Res 2008;23:536-43.

26. Bollag RJ, Zhong Q, Phillips P, et al. Osteoblast-derived cells express functional glucose-dependent insulinotropic peptide receptors. Endocrinology 2000;141:1228-35.

27. McIntosh $\mathrm{CH}$, Wheeler MB, Gelling RW, et al. GIP receptors and signal-transduction mechanisms. Acta Physiol Scand 1996;157:361-5.

28. Zhong Q, Itokawa T, Sridhar S, et al. Effects of glucose-dependent insulinotropic peptide on osteoclast function. Am J Physiol Endocrinol Metab 2007;292:E543-8.

29. Ding KH, Zhong Q, Xu J, et al. Glucose-dependent insulinotropic peptide: differential effects on hepatic artery vs. portal vein endothelial cells. Am J Physiol Endocrinol Metab 2004;286:E773-9.

30. Zaidi M, Shankar VS, Huang CL, et al. Amylin in bone conservation current evidence and hypothetical Considerations. Trends Endocrinol Metab 1993;4:255-9.

31. Garg G, McGuigan FE, Kumar J, et al. Glucose-dependent insulinotropic polypeptide (GIP) and GIP receptor (GIPR) genes: An association analysis of polymorphisms and bone in young and elderly women. Bone Rep 2016;4:23-7.

32. Ranganath L, Sedgwick I, Morgan L, et al. The ageing entero-insular axis. Diabetologia 1998;41:1309-13.

33. Sztefko K, Rogatko I, Milewicz T, et al. Effect of hormone therapy on the enteroinsular axis. Menopause 2005;12:630-8.

34. Nitz I, Fisher E, Weikert C, et al. Association analyses of GIP and GIPR polymorphisms with traits of the metabolic syndrome. Mol Nutr Food Res 2007;51:1046-52.

35. Holst JJ, Gromada J, Nauck MA. The pathogenesis of NIDDM involves a defective expression of the GIP receptor. Diabetologia 1997;40:984-6.

36. Meier JJ, Hücking K, Holst JJ, et al. Reduced insulinotropic effect of gastric inhibitory polypeptide in firstdegree relatives of patients with type 2 diabetes. Diabetes 2001;50:2497-504.

37. Xie D, Cheng H, Hamrick M, et al. Glucose-dependent insulinotropic polypeptide receptor knockout mice have altered bone turnover. Bone 2005;37:759-69.

\section{Figures}

Page $13 / 15$ 

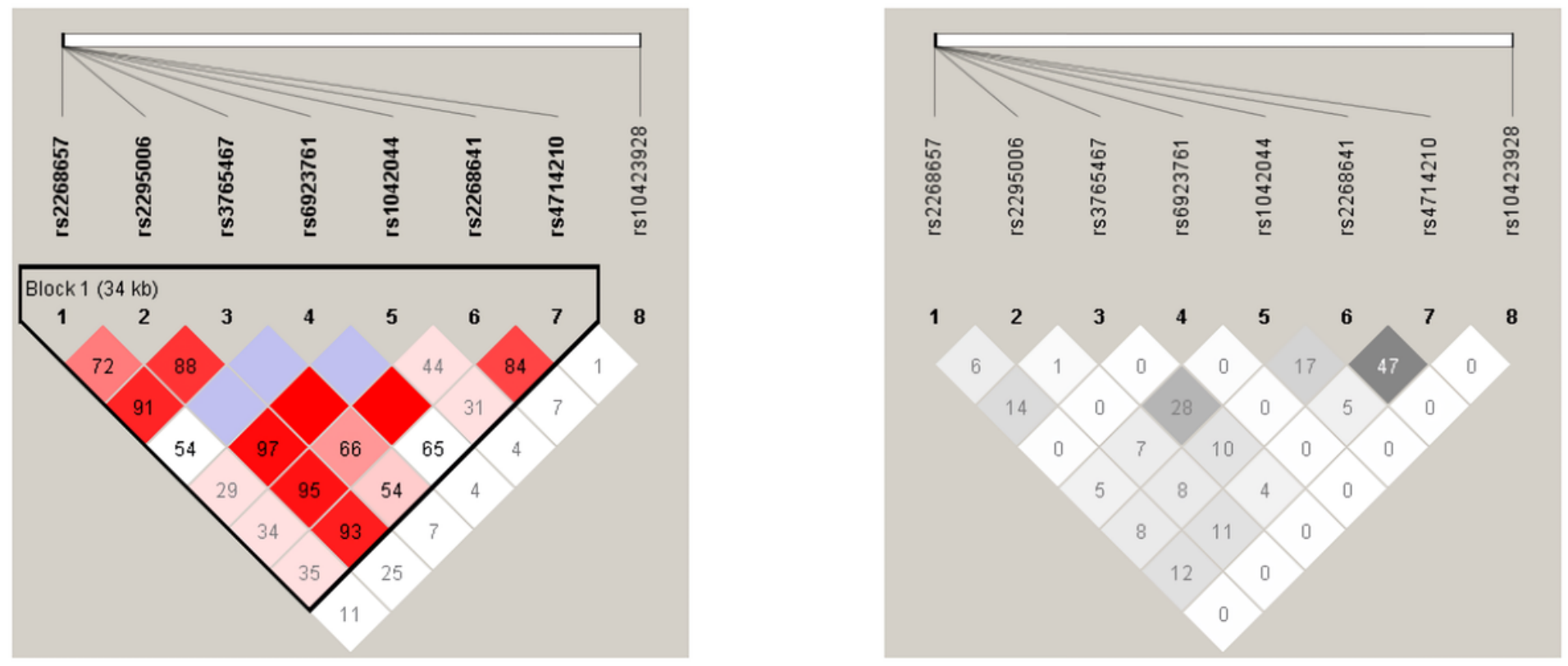

\section{Figure 1}

The linkage disequilibrium diagram of GLP-1R SNPs and GIPR
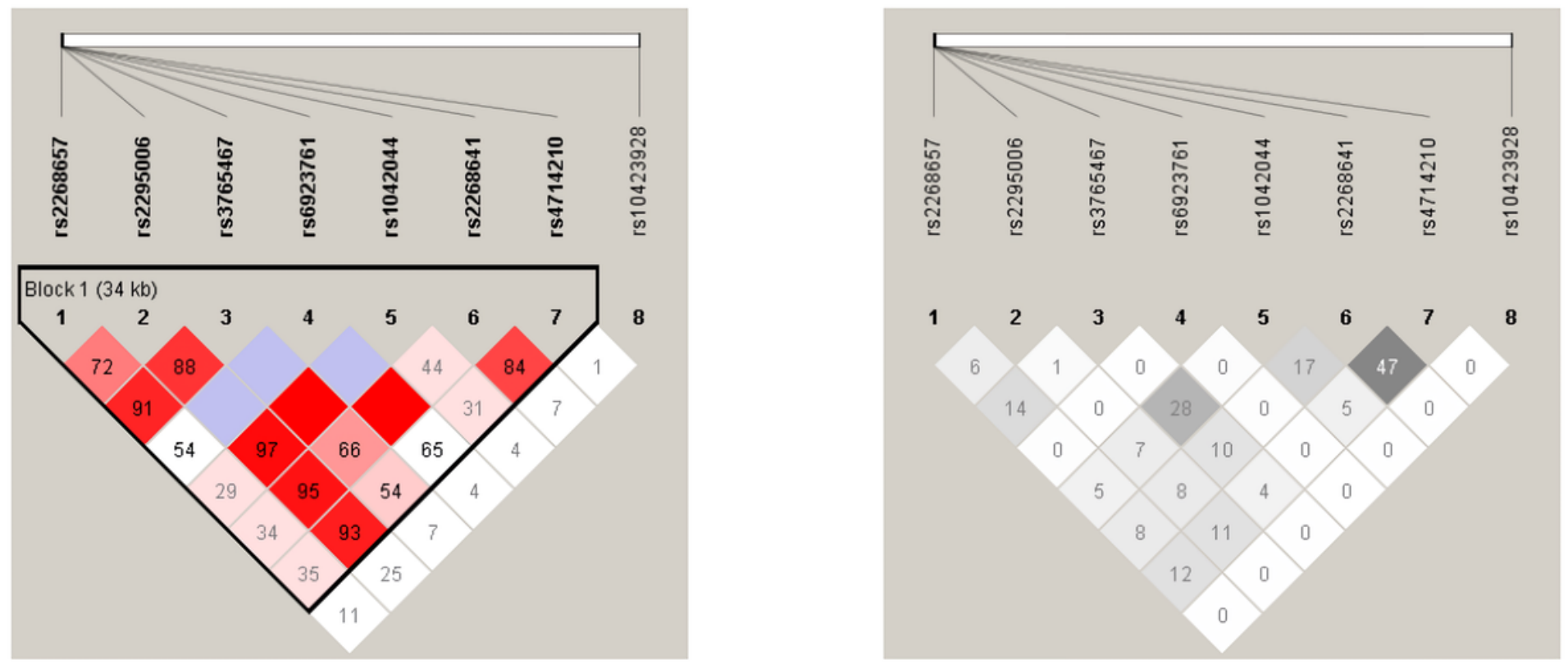

Figure 1

The linkage disequilibrium diagram of GLP-1R SNPs and GIPR 

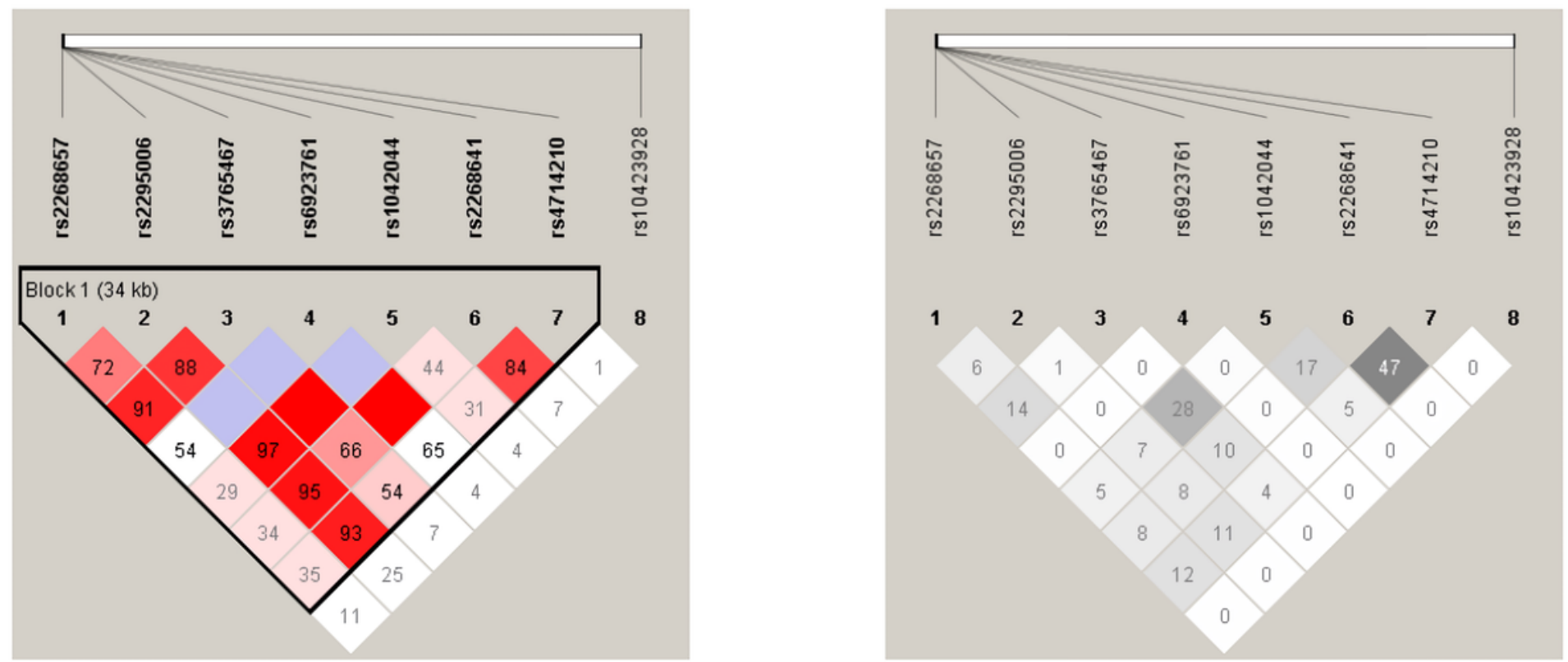

\section{Figure 1}

The linkage disequilibrium diagram of GLP-1R SNPs and GIPR 